\title{
Erişkin Ortotopik Karaciğer Transplantasyonu Sonrası Uzamış Yoğun Bakım Gereksiniminin Ön Belirleyicileri
}

\author{
Predictors for Prolonged Intensive Care Unit Stay After Adult \\ Orthotopic Liver Transplantation
}

\author{
Aycan Kundakcı, Arash Pirat, Özgür Kömürcü, Adnan Torgay, Hamdi Karakayalı*, Gülnaz Arslan, Mehmet Haberal* \\ Başkent Üniversitesi Tıp Fakültesi, Anesteziyoloji Anabilim Dalı, Ankara, Türkiye
}

*Başkent Üniversitesi Tıp Fakültesi, Genel Cerrahi Anabilim Dalı, Ankara, Türkiye

\section{ÖZET}

Amaç: Ortotopik karaciğer transplantasyonundan sonra hastaların erken postoperatif izlemleri yoğun bakımda gerçekleştirilmektedir. Ancak bu hastaların yoğun bakımda kalış süreleri ve bu süreyi belirleyen etkenler tam olarak bilinmemektedir. Uzamıs yoğun bakım yatıs gereksinimi, yoğun bakımların fiziksel ve finansal kaynaklarııı tüketimini arttııırken, hasta sonuçlarını olumsuz etkileyebilir. Bu çalışmanın amacı, erişkin ortotopik karaciğer transplantasyonlarından sonra uzamış yoğun bakım gereksiniminin sıklığını ve buna sebep olabilecek operasyon öncesi sebepleri saptamaktır.

Gereç ve Yöntem: Ocak 2000 - Şubat 2009 tarihleri arasında gerceklestirilen 112 eriskin ortotopik karaciğer transplantasyonunun verileri retrospektif olarak tarandı. Hastaların demografik ve klinik özellikleri, preoperatif laboratuar testleri, intraoperatif hemodinamik parametreler ve yapılan transfüzyonlar, yoğun bakım ve hastane kaIıs süreleri ve mortalite hızları gibi parametreler kaydedildi. Uzamış yoğun bakımda kalıs süresi, transplantasyon sonrası 3 günden uzun yoğun bakım gereksinimi olarak kabul edildi.

Bulgular: Elli dokuz hastada (\%53) uzamış yoğun bakım gereksinimi saptandı. Uzamıs yoğun bakım gereksinimi olan hastalar, olmayanlar ile karsilastırıldığında, model for end-stage liver disease (MELD) ve Child-Pugh skorları daha yüksek (her ikisi için $\mathrm{p}<0,001$ ), preoperatif hemoglobin düzeyleri daha düşük $(p=0,04)$, preoperatif kan üre azotu düzeyleri daha yüksek $(p=0,013)$, koroner arter hastalığı sıklığı daha az $(p=0,046)$, anestezi süreleri daha uzun $(p=0,010)$, intraoperatif hipotansif atak sıklı̆ı daha yüksek $(p=0,013)$ ve intraoperatif kan ürünü transfüzyonu miktarı daha yüksek $(p=0,004)$ bulundu. Istatistiksel olarak anlamlı bulunan bu parametreler ile olusturulan lojistik regresyon modelinde yüksek MELD skoru (OR: 1,4, Cl\%95:1,1-1,7, $\mathrm{p}=0,010$ ) uzamış yoğun bakım gereksinimi için risk faktörü olarak belirlendi. Uzamış yoğun bakım gereksinimi olan hastalar, diğer hastalar ile karșılasstıııldığında daha yüksek mortalite oranlarına sahiptiler (\% $41^{\prime}$ e karssın \% 9, p<0,001).

Sonuç: Sonuç olarak, hastaların \%53'ünde karaciğer transplantasyonu sonrası uzamıs yoğun bakım gereksinimi saptandı ve yüksek MELD skoru bu gereksinim için risk faktörü olarak belirlendi. (Türk Yoğun Bakım Derneği Dergisi 2011: 9: 14-8)

Anahtar Kelimeler: Karaciğer transplantasyonu, uzamış yoğun bakım süresi, MELD skoru

\section{SUMMARY}

Objective: Intensive care unit (ICU) stay consumes physical and financial resources and may increase the risk of complications and possibly mortality. The purpose of this study was to evaluate the factors predicting prolonged ICU length of stay (LOS) after orthotopic liver transplantation (OLT).

Materials and Methods: We reviewed the data of 112 adult patients who underwent OLT between January 2000 and February 2009. The data included the demographic and clinical features, preoperative laboratory values, intraoperative hemodynamic parameters and transfusions, and mortalities. Prolonged ICU LOS was defined as more than 3 days stay in the ICU after OLT.

Results: Out of 112 patients 59 (53\%) of them required prolonged ICU LOS. Patients who required prolonged ICU LOS compared to those who did not had higher model for end stage liver disease (MELD) and Child-Pugh scores $(p<0.001)$, had a lower mean preoperative hemoglobin level $(p=0.04)$, had a higher mean preoperative blood urea nitrogen level $(p=0.013)$, less frequently had coronary artery disease $(p=0.046)$, required higher amounts of blood products transfusions intraoperatively $(p=0.004)$, and had a longer duration of anesthesia $(p=0.010)$. Multivariate logistic regression revealed that only higher MELD scores (odds ratio: 1.4, Cl\%95:1.2-1.7, $p=0.010$ ) was an independent risk factor for prolonged ICU stay after liver transplantation Patients who had developed renal failure in the early postoperative period according to the RIFLE criteria had stayed in the ICU longer [74\% (23) vs 44\%(36), $p=0.006]$. Patients who had stayed in the ICU for more than 3 days had higher rates of mortalities [41\% (24) vs $9 \%(5), p<0.001]$ Conclusion: In conclusion, 53\% of our liver transplant recipients required prolonged ICU stay postoperatively and a higher MELD score was an independent risk factor for prolonged ICU requirement. (Journal of the Turkish Society of Intensive Care 2011; 9: 14-8)

Key words: Liver trasplantation, prolonged icu length of stay, MELD score

Yazışma Adresi/Address for Correspondence: Dr. Aycan Kundakçı, Başkent Üniversitesi Tıp Fakültesi Anesteziyoloji Anabilim Dalı, 10. Sk. No: 45, 06490, Bahçelievler, Ankara, Türkiye Tel.: +90 31221268 68-1172 Faks: +90 3122121583 E-posta: aycan.k@gmail.com

Geliş Tarihi/Received: 29.11.2010 Kabul Tarihi/Accepted: 03.03.2011

Bu çalışma Ocak 2011'de Society of Critical Care Medicine 40th Annual Meeting kapsamında poster bildirisi olarak San Diego'da sunulmuştur.

Türk Yoğun Bakım Derneği Dergisi, Galenos Yayınevi tarafından basılmıștır. / Journal of the Turkish Society of Intensive Care, published by Galenos Publishing. ISNN: $1300-5804$ 


\section{Giriş}

Günümüzde son dönem karaciğer yetmezliğinin tedavisinde tek seçenek olarak kabul edilen ortotopik karaciğer transplantasyonu, cerrahi teknikler ve perioperatif yönetimin gelişmesi ile artan sıklıkta yapılmaktadır. Bu gelişmeler ile birlikte, transplantasyon sonrası kısa ve uzun dönemde daha çok hastaya hizmet verilmektedir. Karaciğer transplantasyonu yapılan hastalar postoperatif erken dönemde yoğun bakımda takip edilmektedir. Yoğun bakım hizmetlerinin ise fiziksel ve finansal kaynakları yüksek oranlarda tükettiği, bunun yanında uzamış yoğun bakım süresinin de enfeksiyon, komplikasyon ve mortalite riskini artırabileceği bildirilmektedir $(1,2)$. Gelişen cerrahi teknikler ve perioperatif bakım ile beraber kısalan cerrahi ve mekanik ventilasyon süreleri postoperatif yoğun bakımda kalış süresini kısaltsa da karaciğer transplantasyonu sonrası uzamış yoğun bakım gereksinimi halen sıktır (3-5). Yoğun bakımda kalış süresinin öngörülebilmesi, cerrahinin doğuracağı yarar-zarar oranlarının belirlenebilmesi yanında, yoğun bakım yataklarının blokajı ile sonraki cerrahilerin planlanabilmesine olanak sağlar. Karaciğer transplantasyonunda postoperatif erken safra üretiminin olmayışı, intraoperatif 20 ünite üzeri trombosit transfüzyonu yapılması, postoperatif erken dönemde idrar çıkışının yeterli olmayışı, postoperatif rejeksiyon ortaya çıkmaSI, gastrointestinal kanama olması, bakteriyel enfeksiyon ve çokluorgan yetmezliği gelişmesi hospitalizasyon süresinin uzaması ile ilişkili bulunmuştur (6-8). Ancak bu faktörlerin önemli bir bölümü postoperatif faktörlerdir ve pre- veya intraoperatif dönemde uzamış yoğun bakım gereksinimi olacak hastaların belirlenmesi için faydalı olamamaktadır.

Bu çalışmada, karaciğer transplantasyonundan sonra uzamış yoğun bakım gereksinimini belirleyen pre- ve intraoperatif değişkenlerin saptanması amaçlanmıştır.

\section{Gereç ve Yöntem}

Etik kurul onayı alındıktan sonra, Ocak 2000-Şubat 2009 tarihleri arasında ortotopik karaciğer transplantasyonu yapılan 112 erişkin hastanın medikal ve anestezi kayıtları retrospektif olarak tarandı. On beş yaşından küçük olan, akut karaciğer yetmezliği olan, kombine böbrek ile karaciğer transplantasyonu yapılan, retransplantasyon yapılan ve postoperatif 3. gün öncesi kaybedilen hastalar çalışma dışı tutuldu. Tüm hastalarda aynı anestezi ve cerrahi teknikler aynı ekipler tarafından uygulandı. Cerrahi sonunda tüm hastalar yoğun bakıma alındı.

Yaş, vücut ağırlığı, cinsiyet gibi demografik özellikler; sigara kullanımı; koroner arter hastalığı, diabetes mellitus ve hipertansiyon gibi eşlik eden hastalıklar; karaciğer yetmezliğinin süresi; hastaların preoperatif asit, hepatik ensefalopati, hepatorenal sendrom, özefageal varis kana- ması, Child-Pugh ve "Model for end stage liver disease" (MELD) skorları ve ejeksiyon fraksiyonları kaydedildi. Child-Pugh skoru için hastaların total bilirubin (mg/dl), albümin (g/dl), INR (International normalized ratio) değerleri yanında asit ve hepatik ensefalopati varlığı, MELD skoru için INR, total bilirubin (mg/dl) ve serum kreatinin (mg/dl) değerleri kaydedildi. Kaydedilen laboratuar değerleri arasında hemoglobin $(\mathrm{g} / \mathrm{dl})$, hematokrit $(\%)$, kan üre nitrojeni (BUN) (mg/dl), serum kreatinin $(\mathrm{mg} / \mathrm{dll})$, sodyum $(\mathrm{mmol} / \mathrm{l})$, potasyum $(\mathrm{mmol} / \mathrm{l})$, aspartat aminotransferaz (AST) (U/I), alanin aminotransferaz (ALT) (U/I), albümin $(\mathrm{g} / \mathrm{dll})$, total ve direkt bilirubin (mg/dl) ve INR yer aldı. Intraoperatif asidoz varlığı, kullanılan sıvı ile kan ürünleri miktarı, "cell saver" kullanımı, komplikasyonlar (bradikardi, hipotansiyon); anestezi ve portal ven klemp süreleri; intraoperatif idrar miktarl; postoperatif akut böbrek hasarı varlığı, yoğun bakım kalış süresi ve mortalite gibi parametreler kaydedildi.

Bu çalışmada > 3 gün yoğun bakımda kalış süresi, uzamış yoğun bakım gereksinimi olarak kabul edildi. Uzamış yoğun bakım yatışı sıklığı ve risk faktörlerini belirleyebilmek amacıyla hastalar yoğun bakımda üç günden az ve üç günden çok kalanlar olarak 2 gruba ayrıldı.

Bütün veriler SPSS yazılımı (Statistical Package for the Social Sciences, version 11.0, SSPS Inc, Chicago, IL, USA) kullanılarak analiz edildi. Çalışmada oluşturulan iki grup verileri ki-kare ve Mann-Whitney $U$ testleri kullanılarak karşılaştııılı. Klinik ve istatistiksel olarak anlamlıık gösteren değişkenler ile, uzamış yoğun bakım kalış süresini öngören risk faktörlerini belirleyebilmek amacıyla lojistik regresyon analizi yapıldı. Veriler, ortalama değerler \pm standard sapma değerleri ile gösterildi. P değeri 0.05 'ten küçük olan analizler anlamlı kabul edildi.

\section{Bulgular}

Analizlere toplam 112 hasta dahil edildi. Ortalama yoğun bakımda yatış süresi 3,6 gündü. Elli dokuz hastada (\%53) uzamış yoğun bakım gereksinimi mevcuttu. Uzamış yoğun bakım gereksinimi olmayanlarla olanlar karşılaştıııldığında preoperatif hemoglobin, kan üre azotu, total ve direkt bilirubin, ve protrombin zamanı değerleri; Child-Pugh ve MELD skorları; ile koroner arter hastalığı, hepatik ensefalopati ve asit sıklığı açısından iki grup arasında anlamlı farklılık saptandı (Tablo 1). Iki grup intraoperatif parametreler açısından karşılaştıııldığında ise uzamış yoğun bakım gereksinimi olan hastalarda anestezi süresi daha uzun, taze donmuş plazma ve eritrosit süspansiyonu transfüzyonu gereksinimi daha fazla ve hipotansiyon atakların sıklığı daha yüksek bulundu (Tablo 2).

Istatistiksel olarak anlamlı bulunan parametrelerden preoperatif hemoglobin ve kan üre azotu, Child-Pugh ve MELD skorları, koroner arter hastalı̆̆ı sıklı̆ı, intraoperatif transfüzyonlar, anestezi süresi ve intraoperatif hipotansi- 
yon sıklığı ile beraber $p$ değeri 0,068 olan ve klinik olarak anlamlı olabileceği düşünülen yaş kullanılarak lojistik regresyon modeli oluşturuldu. Iki grup arasında anlamlı farkllık gösterdikleri halde Child-Pugh veya MELD bileşenlerinden olan serum bilirubin ve INR ile asit ve hepatik ensefalopatinin sıklıkları regresyon modeline dahil edilmedi. Lojistik regresyon analizinde sadece yüksek MELD skorunun (OR: 1.2, Cl\%95:1.1-1.4, $\quad \mathrm{p}=0,001)$ uzamış yoğun bakım gereksinimi için risk faktörü olduğu belirlendi (Tablo 3).

Uzamış yoğun bakım gereksinimi olan grupta postoperatif akut böbrek hasarı sıklı̆ı daha yüksek bulundu (\%73'e karşın \% 40, $\mathrm{p}<0,01)$. Bunun yanında uzamış yo-

Tablo 1. Uzamış yoğun bakım gereksinimi olanlar ile olmayanların demografik ve pretransplantasyon klinik ve laboratuar özellikleri (ortalama \pm standart sapma veya \% (say)

\begin{tabular}{|c|c|c|c|}
\hline & $\begin{array}{c}\text { YB SÜRESI } \\
>3 \text { GÜN ( } n=59)\end{array}$ & $\begin{array}{l}\text { YB SÜRESI } \\
<3 \text { GÜN (n=53) }\end{array}$ & $p$ \\
\hline Erkek cinsiyet & $\% 76(45)$ & $\% 76(40)$ & 1,000 \\
\hline Yaş (yıl) & $42 \pm 14$ & $47 \pm 13$ & 0,063 \\
\hline Ağırlık (kg) & $70 \pm 14$ & $71 \pm 11$ & 0,692 \\
\hline $\begin{array}{l}\text { Karaciğer yetmezlik } \\
\text { süresi (yıl) }\end{array}$ & $4,2 \pm 3,1$ & $6 \pm 5$ & 0,061 \\
\hline MELD & $20 \pm 8$ & $15 \pm 5$ & $<0,001$ \\
\hline Child-Pugh $A, B / C$ & $\begin{array}{l}\% 26(15) / \\
\% 74(43)\end{array}$ & $\begin{array}{l}\text { \%66 (35)/ } \\
\% 34(18)\end{array}$ & $<0,001$ \\
\hline Diabetes mellitus & $\% 17(10)$ & $\% 25(13)$ & 0,356 \\
\hline Koroner arter hastalığı & \%3 (2) & \%15 (8) & 0,045 \\
\hline Hipertansiyon & $\% 9(5)$ & $\% 13(7)$ & 0,544 \\
\hline Hepatik ensefalopati & $\% 51(27)$ & $\% 27(12)$ & 0,036 \\
\hline Özefagus varis kanaması & $\% 57(25)$ & \%37 (13) & 0,113 \\
\hline Asit & $\% 87(46)$ & $\% 48(21)$ & $<0,001$ \\
\hline Hepatorenal sendrom & \%8 (3) & $\% 5(1)$ & 1,000 \\
\hline Akut böbrek hasarı & $\% 12(7)$ & \%6 (3) & 0,328 \\
\hline Hemoglobin (g/dl) & $10,4 \pm 2,0$ & $11,2 \pm 1,8$ & 0,040 \\
\hline BUN (mg/dl) & $24,0 \pm 18,7$ & $16,6 \pm 10,2$ & 0,013 \\
\hline Kreatinin (mg/dl) & $0,96 \pm 0,5$ & $0,86 \pm 0,35$ & 0,241 \\
\hline Sodyum (mmol/l) & $135,3 \pm 4,6$ & $135,6 \pm 3,9$ & 0,685 \\
\hline Potasyum(mmol/l) & $4,19 \pm 0,59$ & $4,21 \pm 0,54$ & 0,840 \\
\hline AST (U/I) & $128 \pm 276$ & $88 \pm 103$ & 0,323 \\
\hline ALT (U/I) & $153 \pm 576$ & $51 \pm 38$ & 0,200 \\
\hline Albümin (g/dl) & $3,20 \pm 0,51$ & $3,22 \pm 0,63$ & 0,840 \\
\hline Total bilirubin (mg/dl) & $9,0 \pm 9,6$ & $4,6 \pm 6,8$ & 0,006 \\
\hline Direkt bilirubin (mg/dl) & $5,8 \pm 8,7$ & $2,4 \pm 4,2$ & 0,010 \\
\hline PTZ (sn) & $22,8 \pm 7,6$ & $18,7 \pm 3,2$ & $<0,001$ \\
\hline INR & $2,1 \pm 0,9$ & $1,6 \pm 0,4$ & $<0,001$ \\
\hline
\end{tabular}

MELD; Model for end stage liver disease, BUN; blood urea nitrogen, AST; aspartat aminotransferaz, ALT; alanin aminotransferaz, PTZ; protrombin zamanı, INR; international normalized ratio ğun bakım sürelerine sahip olan hastalar, diğer grup ile karşılaştıııldığında daha yüksek mortalite oranlarına sahiptiler (\%41'e karşın \%9, $p<0,001)$. Uzamış yoğun bakım intiyacı olmayanlar yoğun bakım taburculuğu ardından tekrar yoğun bakım yatışı gerektikten sonra kaybedilmişlerdir. Uzamış yoğun bakım intiyacı olan hastalar ise yoğun bakımda kaybedilmişlerdir.

\section{Tartışma}

Çalışmamızda, karaciğer transplantasyonu yapılmış erişkin hastaların \%53'ünde uzamış yoğun bakım gereksinimi saptandı. Uzamış yoğun bakım gereksinimi olan hastalar ile olmayanlar karşılaştıııldığında iki grup arasında birçok parametre açısından anlamlı farklılık saptansa da lojistik regresyon analizi sadece MELD skorunun uzamış yoğun bakım gereksinimi için bağımsız risk faktörü olduğunu ortaya koydu.

Uzamış yoğun bakım süresinin tanımıyla ilgili herhangi bir uzlaşı bulunmamakla beraber genel olarak karaciğer transplantasyonundan sonra uzamış yoğun bakım gereksiniminin sık olduğu bildirilmiştir $(3,9,10)$. Biz bu çalışmada günlük pratiğimizden yola çıkarak >3 gün yoğun bakım yatış süresini uzamış yoğun bakım gereksinimi olarak kabul ettik ve bu tanımlamaya göre hastaların \%53'ünde uzamış yoğun bakım gereksinimi saptadık. Literatürde bildirilen uzamış yoğun bakım gereksinimi sıkığı kullanılan farklı tanımlara göre değişkenlik göstermektedir. Ancak retrospektif bir analizde karaciğer transplantasyonundan sonra yoğun bakımda yatış süresinin ortalama 9 gün olarak bildirilmesi bu hastalarda uzamış yoğun bakım gereksiniminin sık olduğunu göstermektedir (9).

\begin{tabular}{|c|c|c|c|}
\hline & $\begin{array}{c}\text { YB SÜRESI } \\
>3 \text { GÜN ( } n=59)\end{array}$ & $\begin{array}{c}\text { YB SÜRESI } \\
<3 \text { GÜN (n=53) }\end{array}$ & $\mathrm{p}$ \\
\hline Anestezi süresi (saat) & $11 \pm 2$ & $10 \pm 2$ & 0,010 \\
\hline Anhepatik faz (dakika) & $86 \pm 41$ & $78 \pm 29$ & 0,254 \\
\hline $\begin{array}{l}\text { Eritrosit süspansiyonu } \\
\text { (ünite) }\end{array}$ & $7 \pm 7$ & $4 \pm 3$ & 0,004 \\
\hline $\begin{array}{l}\text { Taze donmuş plazma } \\
\text { (ünite) }\end{array}$ & $12 \pm 8$ & $7 \pm 4$ & $<0,001$ \\
\hline Kristalloid (ml) & $8004 \pm 3384$ & $7717 \pm 2178$ & 0,599 \\
\hline Kolloid (ml) & $221 \pm 351$ & $160 \pm 322$ & 0,344 \\
\hline Idrar (ml) & $1266 \pm 739$ & $1399 \pm 689$ & 0,329 \\
\hline Hipotansiyon sıklığı & $1,4 \pm 1,5$ & $0,7 \pm 1,1$ & 0,013 \\
\hline Asidoz & $\% 67(35)$ & $\% 55(29)$ & 0,231 \\
\hline Bradikardi & $\% 27$ (14) & \%32 (17) & 0,670 \\
\hline Vazopressör & $\% 60(28)$ & \%63 (32) & 0,836 \\
\hline Inotropik ajan & $\% 52(24)$ & $\% 39(20)$ & 0,225 \\
\hline Antihipertansif & $\% 17$ (9) & $\% 21(11)$ & 0,804 \\
\hline
\end{tabular}


Sumberaz ve ark.'nın (11) karaciğer transplantasyonu sonrası yoğun bakım süresi ile laboratuvar değerlerinin ilişkisini araştırdığı çalışmada, total bilirubin, serum kreatinin ve serum sodyumunun yoğun bakım süresiyle ilişkili olduğu gösterilmiştir. MELD skorlamasının bileşenlerini içeren bu laboratuvar değerlerinin postoperatif yoğun bakım süresiyle ilişkili olması çalışmamızın sonuçlarıyla korelasyon göstermektedir.

MELD skorunun karaciğer transplant alıcılarının sağkalımı üzerindeki etkisi konusunda çelişkili çalışmalar mevcuttur (9,12-15). Tsui TY ve ark.'nın karaciğer transplant alııılarında mortalite için risk faktörlerini araştırdıkları çalışmalarında, yüksek MELD skoru bağımsız bir risk faktörü olarak tespit edilmiștir. Bunun yanında Ferraz-Neto $\mathrm{BH}$ ve ark.'nın çalışmasında yüksek MELD skoru olan hasta grubunda 30-günlük sağkalımın daha yüksek olduğu gösterilirken, yoğun bakımda kalış süreleri daha uzun olarak saptanmıştır. Bu iki çalışmadan farklı olarak Santoyo J ve ark.'nın çalışmasında ise, MELD skorlamasının postoperatif dönemde karaciğer transplant alıcılarında mortalite veya sağkalım için prediktif olmadığı gösterilmiştir. Oberkofler ve ark.'nın (9) 147 karaciğer transplant alııısında, ortalama postoperatif yoğun bakım süresinin 9 gün olduğu çalışmalarında, MELD skorunun >23 olduğu hastalarda yoğun bakım süresinin 10 günü geçtiği bildirilmiştir. Bizim çalışmamızda da MELD skoru > 23 olan hastalarda yoğun bakım süresinin 3 günden uzun olduğu bulundu. Bu sonuçlara göre MELD skorunun karaciğer transplantasyonundan sonra uzamış yoğun bakım gereksiniminin önemli bir göstergesi olarak kullanılabileceğine inanıyoruz.

Karaciğer transplantasyonundan sonra uzamış yoğun bakım gereksinimi için bildirilen diğer bir bağımsız risk faktörü ise verilen intraoperatif kan ürünlerinin miktarıdır.

\begin{tabular}{|c|c|c|c|}
\hline & $\begin{array}{l}\text { Odds } \\
\text { ratio }\end{array}$ & $\begin{array}{c}\text { \%95 güvenlik } \\
\text { aralığı }\end{array}$ & $p$ \\
\hline Yaş & 1,1 & $0,9-1,1$ & 0,219 \\
\hline Koroner arter hastalığı & 1,0 & $0,8-1,2$ & 0,999 \\
\hline MELD skoru & 1,4 & $1,1-1,7$ & 0,010 \\
\hline Child-Pugh skoru & 5,5 & $0,7-45,5$ & 0,109 \\
\hline Preoperatif kan üre azotu & 1,1 & $0,9-1,2$ & 0,193 \\
\hline Preoperatif Hemoglobin & 1,5 & $0,9-2,6$ & 0,117 \\
\hline Anestezi süresi & 1,4 & $0,8-2,3$ & 0,216 \\
\hline Intraoperatif hipotansiyon sıklı̆ı & 1,0 & $0,4-2,5$ & 0,934 \\
\hline Intraoperatif ES transfüzyonu miktarı & 1,2 & $0,8-1,7$ & 0,386 \\
\hline Intraoperatif TDP transfüzyonu miktarı & 1,2 & $0,9-1,4$ & 0,165 \\
\hline
\end{tabular}

MELD, Model for end-stage liver disease; ES, eritrosit süspansiyonu; TDP, taze donmuş plazma
Oberkofler ve ark. (9) çalışmalarında intraoperatif 10 ünite üzerindeki taze donmuş plazma ve 7 ünite üzerindeki eritrosit süspansiyonu transfüzyonlarının uzamış yoğun bakım süresi için bağımsız risk faktörleri olduklarını göstermişlerdir (9). Allojenik taze donmuş plazma transfüzyonu ile inflamasyon, koagülasyon yollarının ve immünolojik reaksiyonların aktivasyonu ile beraber viral ve bakteriyel enfeksiyon insidansının artması ile bu ilişki açıklanabilir (16-18). Bizim çalışmamızda ise uzamış yoğun bakım gereksinimi olmayanlara göre bu gereksinimi gösterenlere daha fazla intraoperatif transfüzyon yapıldı. Ancak, çoklu lojistik regresyon analizinde bu değișkenler uzamıș yoğun bakım gereksinimi için bağımsız risk faktörü olarak saptanmadı. Intraoperatif kan ürünü transfüzyonu miktarı uzamış yoğun bakım gereksinimi için bağımsız risk faktörü olarak bildirilmiş olsa da MELD skoruna göre bu risk faktörünün klinik kullanımı daha kısıtlı olabilmektedir. Bunun nedeni ise bu parametrenin intraoperatif bir değişken olması ve ancak intraoperatif dönemde postoperatif uzamış yoğun bakım gereksinimi konusunda bilgi verebilmesidir. Buna karşın MELD skoru daha preoperatif dönemde bu hususta bilgi sağlayabileceğinden daha değerli olabilir.

Bizim çalışmamızda uzamış yoğun bakım gereksinimi olan hastalarda postoperatif akut böbrek hasarı ve mortaliteye daha sık rastlandı. Karaciğer transplantasyonundan sonra akut böbrek hasarının sık ortaya çıktığı ve bu durumun yüksek MELD skoru ile ilişkili olduğu bildirilmiştir (9). Aynı çalışmada akut böbrek hasarı gelişiminin mortalite ile ilişkili olabileceği de vurgulanmıştır. Bizim çalışmamız, uzamış yoğun bakım gereksinimi ile artmış akut böbrek hasarı ve mortalite arasındaki neden-sonuç ilişkisini ortaya koyabilecek şekilde tasarlanmadığından uzamış yoğun bakım gereksiniminin hasta sonuçlarına etkisi konusunda yorum yapmak mümkün değildir.

Bu çalışmanın iki temel kısıtlıı̆ı̆ mevcuttur. Birincisi ve diğer bütün retrospektif çalışmalarda olduğu gibi sonuçlarımızın sorgulanabilmesine neden olan en temel ksıtlama, çalışmanın retrospektif oluşu ve elde edilen verilerin hasta ve anestezi kayıtlarına dayanmasıdır. Diğer önemli bir sorun ise uzamış yoğun bakımı gereksinimi için yaygın bir uzlaşının bulunmamasıdır. Bu çalışma için uzamış yoğun bakım gereksinimi >3 gün olarak tanımlandı ancak, değişik tanımlamaların kullanılması durumunda farklı sonuçlar elde edilebilir.

Sonuç olarak, karaciğer transplantasyonundan sonra uzamış yoğun bakım gereksinimi ile sık karşılaşılmaktadır. Bizim hasta grubumuzda yüksek MELD skoru uzamış yoğun bakım gereksinimi için bağımsız risk faktörü olarak belirlendi. Uzamış yoğun bakım gereksinimi olmayanlara göre, uzamış yoğun bakım gereksinimi olan hastalarda postoperatif akut böbrek hasarı sıkığı ve mortalite hızı daha yüksek bulundu. Ancak uzamış yoğun bakım gereksinimi ile hasta sonuçları arasındaki ilişkinin incelenmesi için ileri çalışmalara gereksinim vardır. 


\section{Kaynaklar}

1. Bucuvalas JC, Zeng L, Anand R; Studies of Pediatric Liver Transplantation Research Group. Predictors of length of stay for pediatric liver transplant recipients. Liver Transpl 2004;10:1011-7.

2. Gayowski T, Marino IR, Singh N, Doyle H, Wagener M, Fung JJ, et al. Orthotopic liver transplantation in high-risk patients: risk factors associated with mortality and infectious morbidity. Transplantation 1998;65:499-504.

3. Mor E, Cohen J, Erez E, Grozovsky A, Shaharabani E, BarNathan N, et al. Short intensive care unit stay reduces septic complications and improves outcome after liver transplantation. Transplant Proc 2001;33:2939-40.

4. Biancofiore G, Bindi ML, Cellai F, Consani G, Sansevero A, Amorese G, et al. Early tracheal extubation ofter orthotopic liver transplantation. Minerva Anestesiol 1999;65:87-93.

5. Chen SC, Cunneen SA, Colquhoun SD, Shabot MM. Outcomes from nonemergent orthotopic liver transplantation: is postoperative care becoming routine? Am Surg 1998;64:926-9.

6. Bennett-Guerrero E, Feierman DE, Barclay GR, Parides MK, Sheiner PA, Mythen MG, et al. Preoperative and intraoperative predictors of postoperative morbidity, poor graft function, and early rejection in 190 patients undergoing liver transplantation. Arch Surg 2001;136:1177-83.

7. Markmann JF, Markmann JW, Desai NM, Baquerizo A, Singer $J$, Yersiz $H$, et el. Operative parameters that predict the outcomes of hepatic transplantation. J Am Coll Surg 2003;196:566-72.

8. Smith JO, Shiffman ML, Behnke M, Stravitz RT, Luketic VA, Sanyal AJ, et al. Incidence of prolonged length of stay after orthotopic liver transplantation and its influence on outcomes. Liver Transpl 2009;15:273-9.
9. Oberkofler CE, Dutkowski P, Stocker R, Schuepbach RA, Stover JF, Clavien PA, et al. Model of end stage liver disease (MELD) score greater than 23 predicts length of stay in the ICU but not mortality in liver transplant recipients. Crit Care 2010;14:117.

10. Lipsett PA, Swoboda SM, Dickerson J, Ylitalo M, Gordon T, Breslow $\mathrm{M}$, et al. Survival and functional outcome after prolonged intensive care unit stay. Ann Surg 2000;231:262-8.

11. Sumberaz A, Centenaro M, Ansaldi F, Ancarani AO, Andorno E, Icardi $\mathrm{G}$, et al. Relationship between laboratory parameters and intensive care unit stay post-liver transplantation: proposal of a model. Transplant Proc 2007;39:1868-70.

12. Tsui TY, Scherer MN, Schnitzbauer AA, Schlitt HJ, Obed A. Adult living donor liver transplantation: body mass index and MELD score of recipients are independent risk factors for hospital mortality. Langenbecks Arch Surg 2009;394:235-41.

13. Procurement and Transplantation Network [http://www.optn.org]

14. Ferraz-Neto BH, Zurstrassen MP, Hidalgo R, Meira-Filho SP, Rezende MB, Paes AT, et al. Analysis of liver transplantation outcome in patients with MELD Score $>$ or $=30$. Transplant Proc 2008;40:797-9.

15. Santoyo J, Suarez MA, Fernandez-Aguilar JL, Perez Daga JA, Sanchez-Perez B, Ramirez C, et al. True impact of the indication of cirrhosis and the MELD on the results of liver transplantation. Transplant Proc 2006:38:2462-4.

16. Cherry T, Steciuk M, Reddy VV, Marques MB. Transfusion-related acute lung injury: past, present, and future. Am J Clin Pathol 2008; 129:287-97.

17. Klein HG, Spahn DR, Carson JL. Red blood cell transfusion in clinical practice. Lancet 2007;370:415-26.

18. Tinmouth A, Fergusson D, Yee IC, Hébert PC; $A B L E$ Investigators; Canadian Critical Care Trials Group. Clinical consequences of red cell storage in the critically ill. Transfusion 2006;46:2014-27. 